\title{
The binomial of interaction and visualization in digital news media: consolidation, standardization and future challenges
}

\author{
Pere Freixa; Mario Pérez-Montoro; Lluís Codina
}

Nota: Este artículo se puede leer en español en:

http://www.profesionaldelainformacion.com/contenidos/2021/jul/freixa-perez-codina_es.pdf

How to cite this article:

Freixa, Pere; Pérez-Montoro, Mario; Codina, Lluís (2021). "The binomial of interaction and visualization in digital news media: consolidation, standardization and future challenges". Profesional de la información, v. 30, n. 4, e300401.

https://doi.org/10.3145/epi.2021.jul.01

Invited article received on May $31^{\text {st }} 2021$

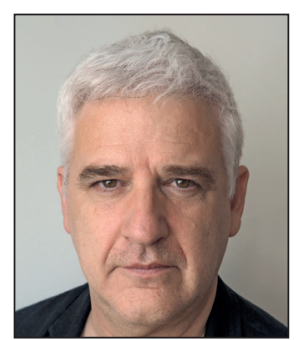

Pere Freixa $\bowtie$

https://orcid.org/0000-0002-9199-1270

Universitat Pompeu Fabra

Departament de Comunicació

Roc Boronat, 138

08018 Barcelona, Spain

pere.freixa@upf.edu

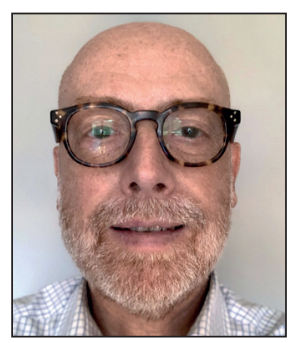

Mario Pérez-Montoro

https://orcid.org/0000-0003-2426-8119

Universitat de Barcelona

Fac. d'Informació i Mitjans Audiovisuals

CRICC Research Center

Melcior de Palau, 140

08014 Barcelona, Spain

perez-montoro@ub.edu

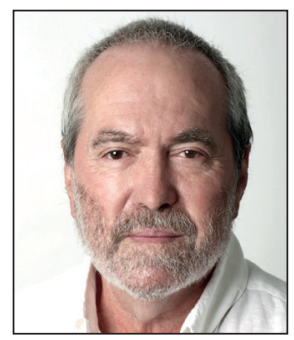
Lluís Codina
https://orcid.org/0000-0001-7020-1631
Universitat Pompeu Fabra
Departament de Comunicació
Roc Boronat, 138. 08018 Barcelona, Spain
UPF Barcelona School of Management
Balmes, 134. 08008 Barcelona, Spain
Iluis.codina@upf.edu

\begin{abstract}
Interaction and visualization together yield an interesting, fruitful, and promising combination for producing content in digital news media. In an era in which the press no longer exclusively provides the news, interaction and visualization combined in innovative products for the public are powerful value propositions for the media. Together, they are capable of winning readers' loyalty and engagement, both of which are crucial for the media's sustainability. In this work, we present a review of the literature and formulate the theoretical bases for this binomial pairing and its main components, which, we argue, should be available to citizens, the interests of whom journalism must defend if it aspires to be viable.
\end{abstract}

\section{Keywords}

Interactive visualizations; Digital journalism; Cyberjournalism; Online media; InfoVis; Digital media; Interactive documentary; Journalistic innovation; Interactive storytelling.

\section{Funding}

This work is part of the project "Interactive storytelling and digital visibility in interactive documentary and structured journalism”. RTI2018-095714-B-C21 (Micinn/Feder). Spanish Ministry of Science, Innovation and Universities. 


\section{Introduction: the binomial of interaction and visualization, a successful pairing}

On 23 March 2020, just a few days after the WHO declared the world Covid-19 pandemic, Navid Mamoon and Gabriel Rasskin, two students from Carnegie Mellon University, launched CovidVisualizer, an interactive visualization application for practically real-time consultation, using a 3D recreation of the globe, of the number of Covid-19 victims and people affected in every country in the world (Figure 1). In just a few weeks it had 70 million users. CovidViualizer is just one of numerous interfaces (Jacob, 2020; Cascón-Katchadourian, 2020; Pérez-Montoro, 2021) that have been created to facilitate understanding and with which to consult the statistical data constantly being recorded about the pandemic. Its success is the result of its authors' skill in designing a device that efficiently combines visualization and interaction. Interactivity, in other words, enables users to explore maps and to establish their own visual narrative.

The media, national agencies and research centres have used interactive resources to construct a narrative of the epidemic with a focus on the aspects about it that are considered most significant (Danielson, 2020). They have offset biased information (Bowe; Simmons; Mat-

tern, 2020) and used visualizations as models with which to forecast the pandemic's evolution (Chen et al., 2020), often revealing how hard it is to standardize and to validate sources of information (Ferrer-Sapena et al., 2020).

Pairing interactivity and visualization as a binomial enhances the media's credibility and increases engagement with users, as it places them at the core of processes of access, dialogue, and relation with data through interfaces (McKenna et al., 2017; Pérez-Montoro; Freixa, 2018).

Thus, for example, in social communication, in contrast with traditional media in which the text of an article of journalism might have told a story using graphs and images to back it up or to endorse what was being narrated, these no longer play such a secondary role in new digital media. Because of their interactive nature, these visual products now occupy a predominant place in telling a story (Pérez-Montoro, 2018). That, at least, is the aspiration of media such as The New York Times, the 2020 targets of which included improving visuals in reports and exploring new dynamics of audience interaction (Leonhardt et al., 2017).

Recognizing the core significance of interaction and visualization in increasingly rich and complex information processes allows for reappraisal of both the practices and the systems that we establish for them to take place. The digital ecosystem has generated its own dynamics that call into question the relationships established among information, what is perceived as narrative, the curation of diverse contents and forms of access, consumption, and participation. It also makes it possible to explore what roles the agents who interact and engage with information should, can or are required to play: journalists, documentalists, information curators, audiences, researchers, informing communities, media, and receiving society (Freixa; Pérez-Montoro; Codina, 2020). Emphasizing the core significance of pairing interaction and visualization also raises questions about how digital text, in a broad sense, is defined, designed, produced, consumed and analysed: multimedia, mutable, modifiable and transmedia.

Use of interactive visualizations in the media has become common practice. They have been consolidated largely because of the standardization both of their formats and of their development, which is a factor that has allowed for a reduction in production costs and more widespread use in newsrooms, as simplification of processes has facilitated their application by editors and journalists who do not have specific training in programming or interaction design.

The consolidation of standardized interactive resources in most newsrooms has released centres of journalistic innovation from the tasks of producing informative content that generally hitherto occupied them. This general circumstance is yielding some interesting consequences:

- First, the standard use of interactive visualizations in all kinds of media plays a significant role in enhancing the literacy of the newsrooms themselves and, particularly, of the audience (Bresciani; Eppler, 2015). The understanding of

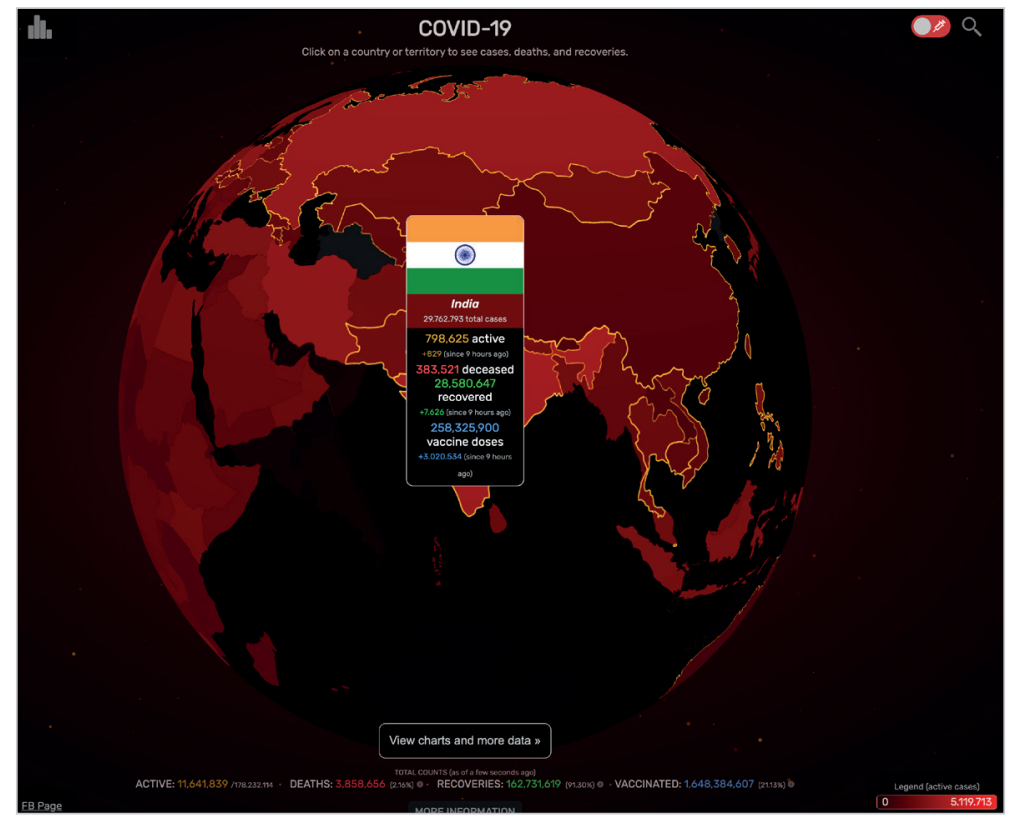

Figure 1. CovidVisualizer interactive real-time data visualization application. https://www.covidvisualizer.com 
maps, graphics, and interactive galleries is becoming standard practice and expanding among users, who would otherwise probably be unaware of their potential for articulating informative narratives.

- Second, it gives research centres the freedom to concentrate on investigating, exploring, and imagining a new generation of interactive audio-visual resources, which are the methods of communication we shall discover and use in the coming decade.
Pairing interactivity and visualization as a binomial enhances the media's credibility and increases engagement with users, as it places them at the core of processes of access, dialogue, and relation with data through interfaces

\section{The history of interactivity and visualization of information in the media}

It is commonly accepted that digital technologies have triggered the transformation of the media and the process of digital convergence, which has been consolidated through the establishment of Internet and social networking sites as a new media ecosystem. Traditional and digital native media have colonized digital space and turned it into the core axis of the media and the stage upon which most information processes are currently articulated. Journalism and journalists have observed both very significant change in their work routines and a transformation of the medium, channels and the methods of designing, producing and transmitting content. Digital media have incorporated interactivity as a defining element, perceiving it as a principle that articulates different functions and technologies used in communication processes. In Jensen's now classic definition, interactivity is

"a measure of a media's potential ability to let the user exert an influence on the content and/or form of the mediated communication" (1998, p. 201).

Interactivity has become an essential concept for understanding a medium characterized by a constant dialogue of inputs and outputs among all the agents and actors involved in it, exchanges that define the medium itself: information that is exchanged, stored, and processed, procedures that mutually feedback to one another to offer a system that enables users to experience and become involved in the information and be part of it (Winograd, 1997). Interaction is considered a value inherent to the medium that, to a greater or lesser extent, characterizes digital text. It is the rhetorical element that differentiates digital text from other formats. It defines exploration as a way of dealing with the text (Aarseth, 1997) and, in the experience of receiving it, allows the narrative value of the explored content to be perceived through it (Ryan, 2004; Cover, 2006). Kate Nash and Richard Walsh characterized interactive work by its capacity to permit the emergence of content in the viewer's process of exploration and interpretation (Walsh, 2011; Nash, 2014).

For most authors, interactivity and participation define the specificity of the digital medium (Boczkowski, 2004; Young; Hermida; Fulda, 2017). Interactivity has been defined on the basis of the semantic capacity of markup language that allows for hypertext and, subsequently, hypermedia links and nodes, a perspective that is established and posited in Nelson and Landow (Nelson,1983; Landow, 1991) and that has been constantly reformulated and expanded (Pavlik, 2001; Aston, 2003, and others). Interactivity, as an inherent element of computational communication, is one of the technological characteristics that have defined and conditioned digital communication and has allowed for the definition of tools and resources for dialogue, in the form of platforms and protocols, procedures and processes. Communication models have thus been defined (Schultz, 1999; Mcmillan, 2002). Despite the different rates of implementation and development (Bachmann; Harlow, 2012; Barredo-Ibáñez; Díaz-Cerveró, 2017), interactivity actually forms part of the current media ecosystem, even though its use has been shown to be limited and, in some cases, more marginal than effective (Palau-Sampio; Sánchez-García, 2020).

Despite their joint presence in a many current areas of journalism, interaction and visualization have not always operated as a binomial pair. The presence of representations of information pre-dates the use of interaction in information processes. It was the job of art departments in the traditional media to construct the graphics and infographics that accompanied texts and that, to a large extent, were intended more to catch the eye than as a source of information (Cairo, 2012). It is, however, also in the process of digitization and transformation from the analogue media system to the digital media ecosystem that different ways of visually representing information have assumed crucial importance. In the cybermedia, their use has increased significantly and become one of the main strategies currently employed by the media to tell stories (Segel; Heer, 2010; Klanten; Ehmann; Schulze, 2011; Chen; Guo, 2020) and to convert data sources into visual information (Weber; Rall, 2012; Pentzold; Fechner, 2020). In contrast with traditional media in which the text of a journalistic article might have told a story using graphs or visualizations to back it up or prove what was being narrated, in new digital media these no longer play this secondary role. Because of its interactive nature, these visual products now occupy a predominant place in storytelling (Pérez-Montoro, 2018; Kalatzi; Bratsas; Veglis, 2018).

The value of visualization lies in its contemplation of meanings and uses that transcend narrative. Because of increasing definition, resolution, and size of screens, particularly on mobile devices, and the implementation in new devices 
of better resources for gestural interaction, unrestricted visual content can be offered, and this plays an important part in catching the attention of and attracting users. For many media, mobile devices have become the main screen for communication with users (Engebretsen; Kennedy; Webber, 2018). In the complex scenario of cybermedia, in which it is still unclear which business models will last and which will not, offering freely accessible information visualizations plays a key role in marketing plans to win audiences that may subsequently consume other paid content or purchase subscriptions. Visualizations of information, with their analyti-

cal and narrative power, can help to attract and keep new users. Thus, for example, some digital media (some of which, but not all, are native), as a strategy, offer a limited number of these types of high-quality products for free, after which the user decides whether it is worth paying and continuing to access these exclusive quality content (Figure 2).

Several authors such as Plaisant (2004) and Smiciklas (2012) confirm the economic return on the investment made in the development (ROI) of visualizations for the cybermedia that include them. Basically, and among other consequences, content that includes visualizations or infographics prompt a significant increase in user interactivity on social media with respect to that content. In some areas, such as political communication, their inclusion has not only increased in recent years but has also marked a change of this sub-genre of news in which they play a crucial role, not only to attract attention, but also as a narrative strategy (Amit-Danhi; Shifman, 2018).

The boom in the presence of interactive visualizations in cybermedia has not been accompanied by a significant increase in academic studies or specific research that offer a better understanding of their multiple dimensions. Although today's cyberjournalism is characterized, among other things, by an intensive use of visualization to tell stories, scientific production and theoretical contributions are neither significant in number nor in importance. Of the scientific literature about data analysis and science, only $0.5 \%$ is devoted to data storytelling and data journalism (Ojo; Heravi, 2018). Moreover, most of this scant production focuses on the study of these types of strategies based on analysis of just a few cases or specific products or on analysis of the production in a specific country or city. Examples of the former can be found in the work of Alexander and Vetere (2011), Stikeleather (2013) and Pouchard, Barton and Zilinski (2014), and others. Significant studies that deal with geographical analysis include those that analyse the development of the practice of these special types of proposals in Sweden (Appelgren; Nygren, 2014), Norway (Karlsen; Stavelin, 2014), and Belgium (De-Maeyer et al. 2015), the United Kingdom (Knight, 2015) and the United States (Parasie; Dagiral, 2013; Fink; Anderson, 2014; Parasie, 2015).

There is only one small series of proposals that has addressed this area of study from a broader or more systematic perspective. These can be classified into three large groups. The first of these groups includes proposals that attempt analysis focused mainly on the representative capacity -sometimes not in the context of journalism- of data visualization (Tufte, 1983; Few, 2012; and Cairo, 2017b; and others). The second group proposes dichotomous analysis and the division of current visual works into two large groups, in accordance with criteria associated with their architectural structure such as the browsing system they use (McKenna et al., 2017).

As an alternative, there are also proposals that approach these productions from a polyhedral perspective. The proposals from the third group are therefore grouped together: faceted analyses that attempt to explain the phenomenon of visualization in the cybermedia. These proposals adopt different perspectives or different criteria (facets) to simultaneously classify the same set of objects (the classification domain), thus increasing their explanatory power over and above simple hierarchical analyses.

Some faceted studies do attempt to cover this analysis of visual narratives with data (including Segel; Heer, 2010; and Lee et al., 2015). There are, however, explanatory limitations to these proposals as they do not in-
For most authors, interactivity and participation define the specificity of the digital medium 
clusively and simultaneously address all, but rather just a part, of the characteristics of these visual productions. They contemplate aspects such as narrative genre, visual narrative, narrative structure, and interaction, while leaving out and not analysing all the dimensions related to architectural aspects (organizational, navigational, and labelling systems, mainly) and the visualization-story ratio (Pérez-Montoro, 2018).

\section{Research and standardization. Tools and resources for digital newsrooms}

The consolidation of interactive visualizations in digital newsrooms is largely due to the standardization of a series of basic resources that writers and editors now generally have at their disposal. In designing the news, in addition to texts, authors may also contemplate the use of interactive visualization resources with which to present the audience with the data gathered, images and the archive material consulted while preparing the information. For many professionals, the use of visualizations has been possible because of the

"the development of easy-to- use software, helping non-specialist journalists to make their own simple visualizations" (Engebretsen; Kennedy; Webber, 2018, p. 10).

These resources may be semantic (maps, timelines, bar graphs, etc.) or morphological (ordered by format, type, duration, etc.). Producing interactive information mainly involves the task of assembling modular resources. The authors of the items decide on both the content to be presented and the hierarchy with which the interface is organized. Some methods of constructing an interactive narrative, such as parallax scrolling (Freixa et al., 2014; Córdoba-Cabús, 2020), are very well-established, have proven to be effective in different areas and specialities (Tulloch; Ramon, 2017) and provide the basis for many large-format items (Hiippala, 2017; Dowling, 2019), also referred to as literary journalism (Jacobson; Marino; Gutsche, 2015) or narrative journalism (Van-Krieken; Sanders, 2019).

The emergence of data visualization as interactive resources led to the incorporation of specialists in newsrooms (Ferreras-Rodríguez, 2013). The development of specific applications has, however, prompted a gradual reduction in their cost and difficulty of implementation. The use of maps or timelines, to name two of the currently most broadly used interactive visualizations for geolocating and temporizing information, require decreasingly specialized equipment in newsrooms. The media have numerous tools for facilitating the creation and incorporation of visualizations in the body of the news. Good examples of these are Datawrapper, Maps4news, both of which are paid solutions, although there also exist free applications like StoryMap and both free and paid solutions such as Google Flourish.

https://www.datawrapper.de

https://maps4news.com

https://storymap.knightlab.com

https://flourish.studio

The specialization or non-specialization of newsrooms and the incorporation of specialized profiles have both been a significant feature of

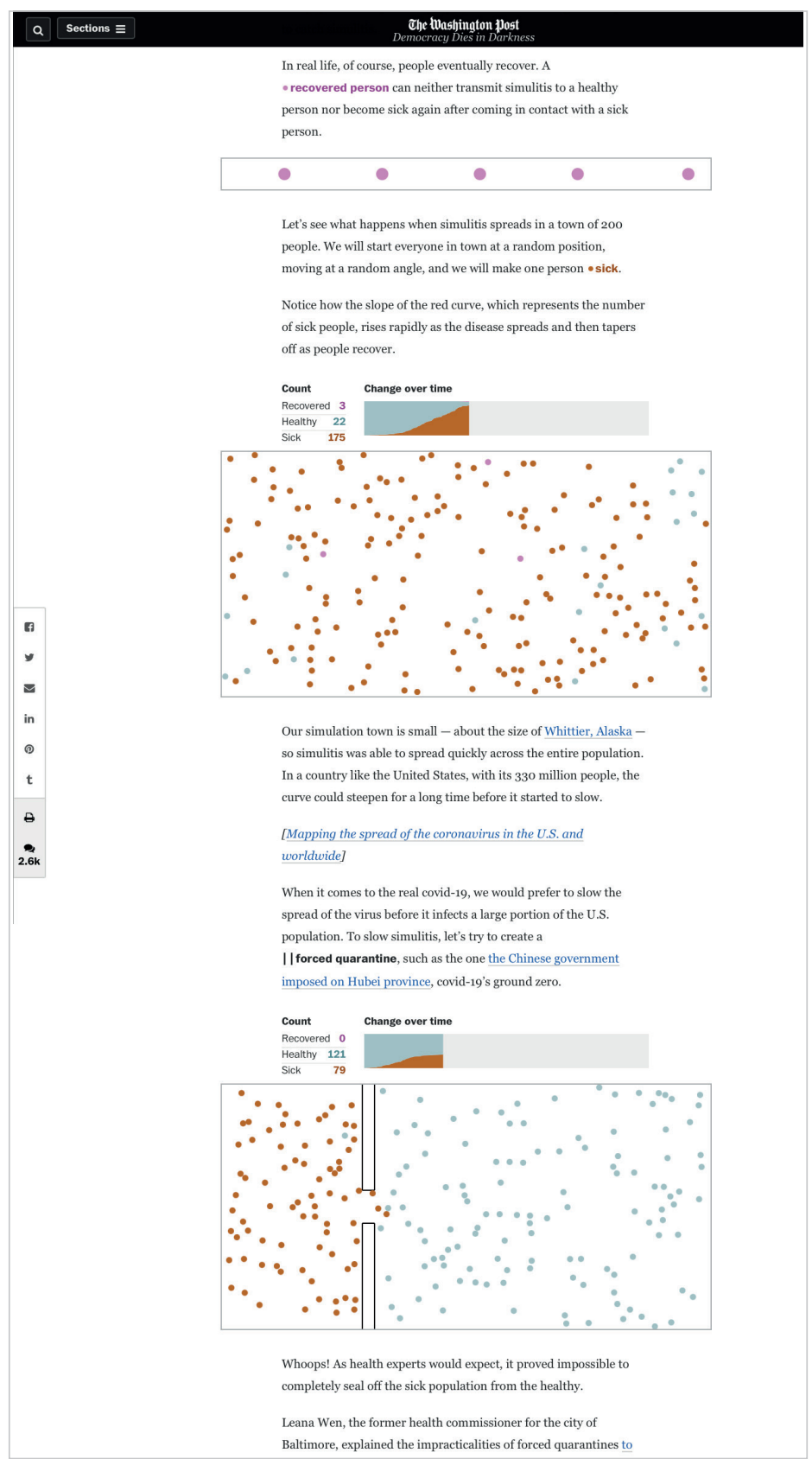
coronavirus spread exponentially, and how to 'flatten the curve'", created by The Washington Post on March 14, 2020.

https://www.washingtonpost.com/graphics/2020/world/corona-simulator
Figure 3. Interface with interactive visualizations of the report "Why outbreaks like 
the process of establishing interactive resources in digital media (Ribas; Freixa 1997; Soler-Adillon et al., 2016; Caminero-Fernández; Sánchez-García, 2018). At the start of this century, the high cost and the training requirements greatly limited how widely they were used. Standardization of resources has therefore been one of the challenges pursued by research centres and journalism innovation laboratories in recent years, as has the simplification of implementation procedures.
The boom in the presence of interactive visualizations in cybermedia has not been accompanied by a significant increase in academic studies or specific research that offer a better understanding of their multiple dimensions

International research centres and innovation laboratories such as the MIT Open Documentalism Lab, the BBC News $L a b$, the Reuters Institute, and the Nieman Foundation, to mention the most obvious, have explored the potential of visualization and interaction resources as a major part of the design of new formats of journalism (Salaverría, 2015; López-García, Rodríguez-Vázquez; Pereira-Fariña, 2017). Projects that use interactive visualizations

"directly enhance both data literacy and legibility, and at the same time, they stimulate user participation" (Uricchio, 2016, p. 24).

The Reuters Institute predictions for 2021 appear to confirm those forecasts:

"The Washington Post's coronavirus simulator was its most viewed story ever and helped make the case for the establishment of a new department of seven journalists which will start this year" (Newman, 2021, p. 11).

The BBC Lab has been performing the Optimo project, which is a tool for transforming textual stories into visual and interactive narratives, designed for mobile telephones (Caswell, 2019). Research into innovation in journalism has become a productive area that addresses different dimensions (Paucar-Carrión; Coronel-Salas, 2019; García-Avilés, 2021) which significantly include experimentation with the narrative forms possible with digital medium and networks, one of the areas of innovation with the greatest potential for growth.

\section{Making the invisible accessible and visible. Limitations and problems}

The binomial pairing of interaction and visualization in the media would be incomplete without mention also of the information that feeds the news items, information that can be both self-produced or collected from one or several sources (Guallar; Codina, 2018). Visualization of information has grown so rapidly because of its effectiveness in transforming hard-to-interpret and to-analyse content into visual representation. What is known as data journalism is formalized on screen through visualizations, which are becoming increasingly interactive (Burmester et al., 2010). As mentioned previously, visual information not only attracts the audience's attention, but also effectively makes it possible to view complex data (Cairo, 2017a). The transformation of complex sets of information and data into interactive visual resources gives rise to problems of a different kind such as legibility (Uricchio, 2016), opacity (Zamith, 2019), and difficulty in accessing data sources and/or verifying them (Porlezza; Splendore, 2019; Lewis; Al Nashmi, 2019). Journalism and multimedia documentaries turn data into narratives through which they can be explained and contextualized. The process, however, involves decision-making about the formalization, functionality and legibility of the sources and these aspects can cause the audience to lose capacity for interpretation, reading and access (Appelgren, 2018).

Converting complex data and information into visualizations is not always an easy task, particularly when visualization entails expressing graphically equations, formulas and algorithms that act on the data. Although interactive visualizations have amply proven their ability to turn this type of information into audio-visual narrative, several authors have sounded warnings about the possibilities of bias and error in such visualizations, which McNutt, Kindlmann and Correll (2020) refer to as visualization mirages.

The apparent accuracy of representations on a graph about Covid-19 or about electoral results, to mention some recent examples, may conceal errors that yield misleading results, which often go unnoticed by the authors themselves. These may be due to problems with backup data, or source data, with which there may be issues because of bias, because they are incomplete or because they have been wrongly combined (Tang; Wu; Li, 2019), and what are known as dirty data (Kim et al., 2003) which require tools and verification processes (Kasica; Berret; Munzner, 2020).

Errors can occur:

- even if correct and well-coded data sources are available during the visualization design process;

- because are the result of interaction that causes frustration on account of its ineffectiveness, or that satisfies neither readers' expectations nor fulfils the data's potential (Appelgren, 2018);

- due to the complexity of the item and its interactive potential are not explored by a significant volume of readers (Young; Hermida; Fulda, 2017);

- because of reading or interpretation errors. 
The most common errors in the design of interactive visualizations include classic infographic problems such as misuse or manipulation of scale, a process that accentuates the appearance because of inadequate or excessive data, which is known as hidden uncertainty. Table 1 shows the errors most commonly encountered by different authors according to the four categories listed.
What is known as data journalism is formalized on screen through visualizations, which are becoming increasingly interactive

Table 1. Malpractice, mirages, and most common errors in interactive visualizations

\begin{tabular}{|c|c|c|}
\hline Area & Error & Effect caused \\
\hline \multirow{4}{*}{$\begin{array}{l}\text { Backup data: elici- } \\
\text { tation, curatorship, } \\
\text { and screening }\end{array}$} & Lost or repeated registrations & Incorporation of data or inexact groupings in the visualization. \\
\hline & Atypical or abnormal values & $\begin{array}{l}\text { Some statistical parameters can yield atypical values, generally at the ends of } \\
\text { the graphs, which can distort interpretation of the graphs. }\end{array}$ \\
\hline & Attribution errors & $\begin{array}{l}\text { Unspecific coding or overly interpretable allocation criteria may yield ambi- } \\
\text { guous data sets, which may lead to significant biases when combined with } \\
\text { other indicators in multiple comparisons. }\end{array}$ \\
\hline & Sample size & $\begin{array}{l}\text { Excessive and inadequate. The choice of significant samples to demonstrate } \\
\text { a certain hypothesis may give rise to HARKing (hypothesizing after the results } \\
\text { are known). In other situations, imbalance among groups of values may raise } \\
\text { doubts about the results of multiple comparisons. }\end{array}$ \\
\hline \multirow{3}{*}{$\begin{array}{l}\text { Design of the } \\
\text { visualization }\end{array}$} & Graphic noise & $\begin{array}{l}\text { The visualization contains decorative elements that could be interpreted as } \\
\text { misleading information. }\end{array}$ \\
\hline & Overlays & $\begin{array}{l}\text { The design chosen for the visualization does not allow for good distribution of } \\
\text { the data and there are content overlaps that affect understanding. }\end{array}$ \\
\hline & Uncertainty & $\begin{array}{l}\text { Grouping content by area may lead to incorrect or difficult visual comparisons, } \\
\text { just as amplification or modification of the scale may lead to errors in data } \\
\text { interpretation. }\end{array}$ \\
\hline \multirow{5}{*}{ Interaction } & Insubstantiality & Interactivity with visualization is irrelevant and does not add meaning. \\
\hline & Loss of agency & $\begin{array}{l}\text { The behaviour of the interaction does not provide the user with a perception } \\
\text { of agency. It does not allow users to construct their own itinerary or to create a } \\
\text { personalized interpretation. }\end{array}$ \\
\hline & Inaccessible interaction & $\begin{array}{l}\text { Interaction with the interactive resource does not allow consultation and } \\
\text { access to the supporting data. }\end{array}$ \\
\hline & Limited participation & $\begin{array}{l}\text { In scenarios in which users could offer opinion, content or their own experien- } \\
\text { ce arising from interaction with the resource, the system does not provide for } \\
\text { feedback. }\end{array}$ \\
\hline & Invisibility in participation & $\begin{array}{l}\text { The system records browsing data, asks users for opinions, and compiles } \\
\text { information provided by them, but does not offer feedback either through } \\
\text { visualization or other mechanisms. }\end{array}$ \\
\hline \multirow{4}{*}{$\begin{array}{l}\text { Interpretation and } \\
\text { reading }\end{array}$} & Default biases & $\begin{array}{l}\text { The visualization design tools offer default combinations intended to make } \\
\text { work easier for authors. Depending on how they are used, however, the results } \\
\text { may be erroneous because of their poor adaptation to the data sets. }\end{array}$ \\
\hline & Inaccessible visualizations & $\begin{array}{l}\text { The choice of a single visualization option turns users into a homogeneous } \\
\text { group. Viewing problems or deficient devices may cause misinterpretations } \\
\text { and reading errors. }\end{array}$ \\
\hline & Anchor effect and reading errors & $\begin{array}{l}\text { When observing sets of visualizations, initial interpretations tend to condition } \\
\text { the later readings. Possible variations in visualizations may go unnoticed by } \\
\text { users. }\end{array}$ \\
\hline & Interpretive and confirmation biases & $\begin{array}{l}\text { The audience context conditions interaction and reading of interactive visuali- } \\
\text { zations. Confirmation bias occurs when viewers look at data that confirm their } \\
\text { hypotheses or preconceptions, and the evidence in its entirety is ignored. }\end{array}$ \\
\hline
\end{tabular}

Source: Own elaboration from McNutt, Kindlmann and Correll (2020), Uricchio (2016), Cairo (2017a), Zamith (2019), Appelgren (2018), and Porlezza and Splendore (2019).

Interactive visualizations reveal the duality of their function by allowing not only a clearly authorial function of an explanatory nature, but also the enormous exploratory potential of audiences (Barlow, 2014, Kirk, 2016). The promise of exploration remains one of the conflicting aspects of interactive journalism and data journalism, discerned as a possibly oversized scenario (Domingo, 2008) that lies somewhere between what could be and what eventually actually is.

\section{Challenges of innovation and future trends}

The standardization of interactive visualization resources is facilitating access to these media by non-specialized newsrooms and small and medium-sized media. This circumstance is also accompanied by increasing knowledge among journalists of the communication possibilities and potential of visualizations. Greater ease of execution and general 
improvement in training (in narration with data, in interactive potential, in type and function of visualizations) makes it likely that, in the coming years, interactive visual resources are likely to become commonplace and used fully in digital newsrooms.

\subsection{Complex visual and interactive narratives}

For Albers (2015), complex narratives are those that offer users the chance to establish comparisons of relationships and different data (flat information) and visualizations that establish a certain information flow and require a defined reading sequence (information flow process). Their classification is still conditioned by difficulties of description. In the study by Córdoba-Cabús (2020), for example, one type of complex visualization, which requires users to enter values or variables, is classified in the other section as it is hard to reduce them to a single dominant element. Specialists such as Cairo (2012) and McCandless (2014) defend the capacity of complex visualizations as a resource that allows concepts and information to emerge through the conversion of interrelated data sets.

Complex visualizations, however, pose significant challenges, basically associated with the difficulties involved in correctly articulating multiple comparisons and giving them visual coherence, narrativity and rigour, and ensuring that the audience interacting with them understands them properly. Some experiences place advances in visualizations at the confluence of these resources with augmented reality (Aitamurto et al., 2020; Tejero-Calvo et al., 2020) and with immersive non-fiction in virtual reality (De-la-Peña et al., 2010; Wang; Gu; Suh, 2018), which are environments that encourage the perception of presence and greater interaction of audiences (Roberts, 2018).

\subsection{Interactive visualizations in news- rooms}

Not only does the incorporation of complex interactive visualizations offer a chance to communicate with audiences, but their development and implementation in newsrooms is helping journalists to obtain data and information. The production of complex visualizations enables newsrooms to research data analysis, interrelationships among data and the possible ways in which they may become effective visualizations (Howe et al., 2017; Engebretsen; Kennedy; Weber, 2018). Newsrooms have incorporated data visualization tools as further resources with which to select content and design news (Wang; Diakopoulos, 2021).

In long journalistic formats, such as interactive documentaries or large-format reports, in which multimedia contents are combined with one another to offer readers an interactive narrative experience (Freixa, 2018), the traditional phases of ideation, data gathering, and production of information have changed considerably. Processes, which involve teamwork, often become intermingled and provide mutual feedback (Planer; GoduIla, 2020). Visualizations and prototypes are part of the process.

\subsection{Optimization and SEO of interactive resources}

Digital journalism, to be sustainable (Apablaza-Campos; Codina; Pedraza-Jiménez, 2018), needs to reach its audiences through different platforms and particularly through the results pages of search engines and of social media such as Facebook and Twitter. Although the ideal situation would be for the news to be consumed on the portal of the medium

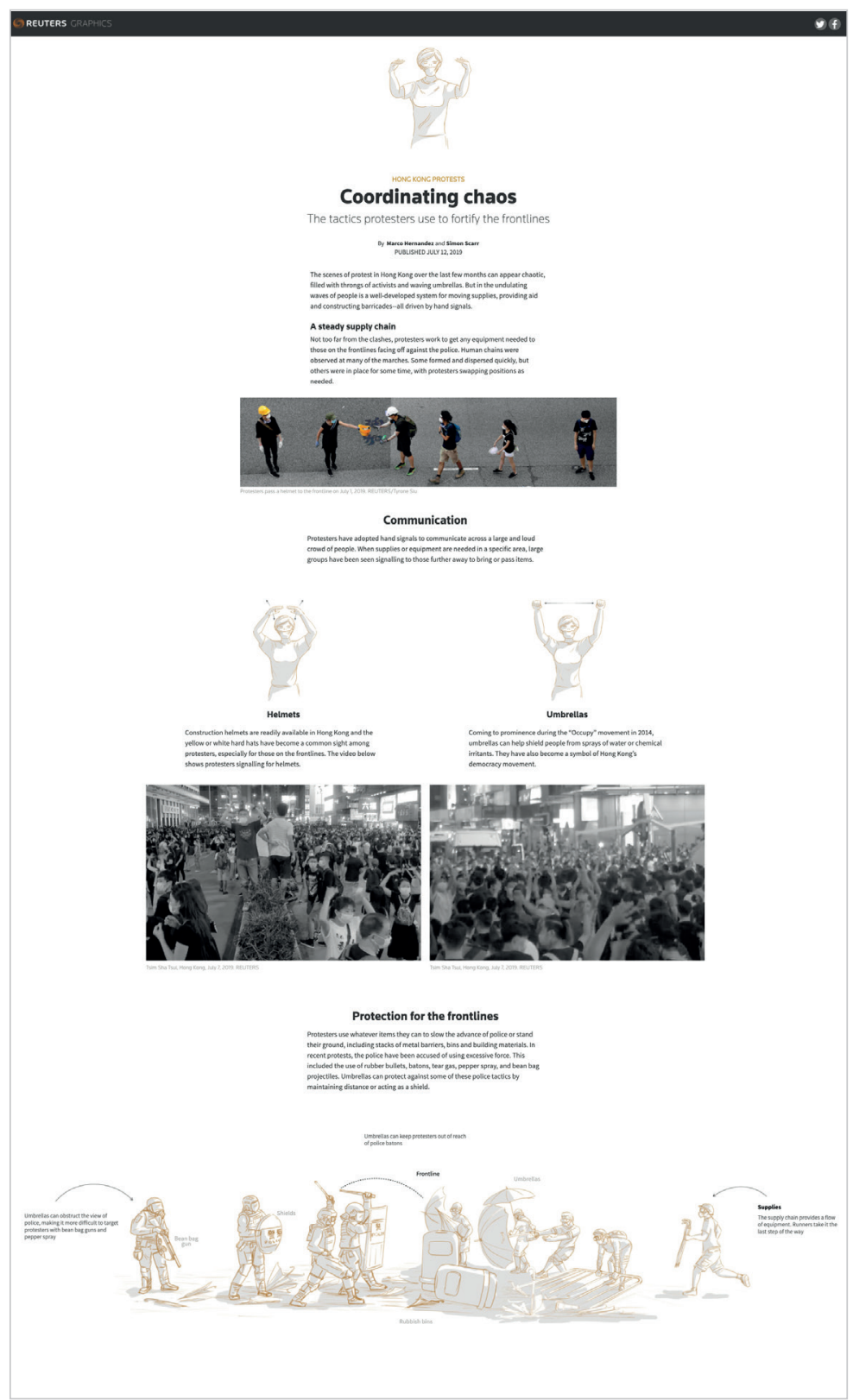

Figure 4. Interactive report Visualizing the Hong Kong protests, from Reuters, showing different uses of image processing and analysis. He was awarded an OJA award in 2020. http://graphics.reuters.com/HONGKONG-EXTRADITION-CROWDSIZE/0100B05WOBE/ index.html 
itself, readers use the platforms mentioned above as intermediary channels. A significant amount of traffic therefore arrives through digital platforms and, mainly, through Google's search engine and its mobile applications such as Google Discover. What this tells us is that digital media should invest resources in the what is known as Search Engine Optimization, or by its popular acronym SEO, to ensure that their productions reach their addressees in peak condition (Codina et al., 2016, Pérez-Montoro; Codina, 2017).

Fortunately, for some time now the best journalism has not followed the dreadful practice of "writing for Google", but has rather considered and adapted to the characteristics of the digital medium. This is the same what once occurred in journalism with radio and television. With SEO, newsroom journalists should understand the characteristics of the digital medium and, in particular, should have a proper conceptual knowledge of the algorithms that affect the visibility of news in search engines and in applications such as Discover or in Facebook or Twitter newsfeed.

In turn, the strategic SEO managers in each newsroom should help writer journalists to choose the best news focus and in matters such as the use of keywords, or how to apply the principles of twin nomenclature -journalistic and SEO- with the help of metadata, among other resources (Lopezosa et al., 2020). The essential idea is for the SEO to ensure that the best journalism reaches its natural audience, without the quality of the news or medium's productions being affected by anything that is not of use to society. It is this society that the medium represents and whose interests it should defend first and foremost in order to justify itself in an era of abundant information and the loss of the media's news exclusivity.

\subsection{Standardization and specialization}

In a recent study, Link, Henke and Möhring (2021) call into question improvements brought by interactive visualizations insofar as the credibility of the message of journalism is concerned. They nonetheless note that the audience perceives a better reading experience because of interaction with interactive visualization resources. The potential of interactive visualizations to arouse interest and to motivate readers is broadly demonstrated in the media (Lee; Kim, 2016; Greussing; Kessler; Boomgaarden, 2020) and in specialist areas such as medical communication (Oh; Hwang; Lim, 2020).

The appeal of interactive visualizations and their greater capacity to motivate may convince digital media enough to use them more and to make a commitment to them. The predominance of simple visualizations (Loosen; Reimer; De-Silva-Schmidt, 2017; Young; Hermida; Fulda, 2017) highlights how visualization creation tools have penetrated newsrooms on a fairly general basis and have allowed for some standardization of basic interactive visualizations such as timelines, interactive charts and maps, and interactive infographics and animations.

To date, only a small number of digital media with specialized teams in data journalism, structured journalism, large format journalism and interactive documentary have committed themselves to further development of the communicative potential that interactive visualizations can bring to cybermedia. Improvement in the development of specific applications and easier access to reliable and contrasted data sources will allow -bearing in mind the evolution in recent years-for general use of real-time visualizations, now possible because of Covid-19, and for more complex visualizations in an increasing number of digital newsrooms.

\section{Conclusions}

We have examined the different perspectives that influence the binomial pairing of interaction and visualization analysed in our research. We have established that both interaction and visualization will have a huge impact on the future of digital journalism.

This pairing can help to build audience loyalty and to demonstrate the media's commitment to its readers and to the society it is supposed to represent and whose interests it is required to defend.

Interaction and visualization, together with other elements not considered here because of obvious limitations of space, such as solutions journalism or structured journalism, to mention two other areas, therefore both represent a fruitful field of research for academics and offer a range of opportunities for professionals.

\section{References}

Aarseth, Espen J. (1997). Cybertext: Perspectives on ergodic literature. Maryland: Johns Hopkins University Press. ISBN: 9780801855795

Aitamurto, Tanja; Aymerich-Franch, Laura; Saldívar, Jorge; Kircos, Catherine; Sadeghi, Yasamin; Sakshuwong, Sukolsak (2020). "Examining augmented reality in journalism: Presence, knowledge gain, and perceived visual authenticity". New media \& society, online first.

https://doi.org/10.1177/1461444820951925 
Albers, Michael J. (2015). "Infographics and communicating complex information". In: Marcus Aaron (ed.). Design, user experience, and usability: Users and interactions, pp. 267-276. Cham: Springer.

https://doi.org/10.1007/978-3-319-20898-5_26

Alexander, Stephanie; Vetere, Colleen (2011). "Telling the data story the right way". Healthcare financial management, v. 65 , n. 10 , pp. $104-110$.

https://go.gale.com/ps/anonymous?id=GALE\%7CA274025520

Amit-Danhi, Eedan R.; Shifman, Limor (2018). "Digital political infographics: A rhetorical palette of an emergent genre". New media \& society, v. 20, n. 10, pp. 3540-3559.

https://doi.org/10.1177/1461444817750565

Apablaza-Campos, Alexis; Codina, Lluís; Pedraza-Jiménez, Rafael (2018). “Newsonomics in the interactive era: Dimensions of sustainability in the news media". In: Pérez-Montoro, Mario (ed.). Interaction in digital news media. Cham: Palgrave Macmillan (Springer), pp. 115-146.

Appelgren, Ester (2018). "An illusion of interactivity: The paternalistic side of data journalism". Journalism practice, v. 12, n. 3, pp. 308-325.

https://doi.org/10.1080/17512786.2017.1299032

Appelgren, Ester; Nygren, Gunnar (2014). "Data journalism in Sweden: Introducing new methods and genres of journalism into "old" organizations". Digital journalism, v. 2, n. 3, pp. 394-405.

https://doi.org/10.1080/21670811.2014.884344

Aston, Judith Y. (2003). Interactive multimedia: an investigation into its potential for communicating ideas and arguments. [Doctoral thesis]. London: Royal College of Art.

Bachmann, Ingrid; Harlow, Summer (2012). "Interactividad y multimedialidad en periódicos latinoamericanos: avances en una transición incompleta". Cuadernos de información, n. 30, pp. 41-52.

https://doi.org/10.7764/cdi.30.421

Barlow, Mike (2014). Data visualization: A new language for storytelling. Sebastopol, CA: O’Reilly Media. ISBN: 9781 491945032

Barredo-Ibáñez, Daniel; Díaz-Cerveró, Elba (2017): “La interactividad en el periodismo digital latinoamericano. Un análisis de los principales cibermedios de Colombia, México y Ecuador (2016)”. Revista latina de comunicación social, n. 72 , pp. 273-294.

https://doi.org/10.4185/RLCS-2017-1165

Boczkowski, Pablo J. (2004). "The processes of adopting multimedia and interactivity in three online newsrooms". Journal of communication, v. 54, n. 2, pp. 197-213.

https://doi.org/10.1093/joc/54.2.197

Bowe, Emily; Simmons, Erin; Mattern, Shannon (2020). "Learning from lines: Critical Covid data visualizations and the quarantine quotidian”. Big data \& society, v. 7, n. 2, 2053951720939236.

https://doi.org/10.1177/2053951720939236

Bresciani, Sabrina; Eppler, Martin J. (2015). "The pitfalls of visual representations: A review and classification of common errors made while designing and interpreting visualizations". Sage open, v. 5, n. 4.

https://doi.org/10.1177/2158244015611451

Burmester, Michael; Mast, Marcus; Tille, Ralph; Weber, Wibke (2010). "How users perceive and use interactive information graphics: An exploratory study." IEEE Proceedings of the $14^{\text {th }}$ international conference information visualization (IV 10), London, pp. 361-368.

https://doi.ieeecomputersociety.org/10.1109/IV.2010.57

Cairo, Alberto (2012). The functional art: An introduction to information graphics and visualization. Berkeley: New Riders. ISBN: 9780321834737

Cairo, Alberto (2017a). "Visualización de datos: una imagen puede valer más que mil números, pero no siempre más que mil palabras". El profesional de la información, v. 26, n. 6, pp. 1025-1028.

https://doi.org/10.3145/epi.2017.nov.02

Cairo, Alberto (2017b). Nerd journalism: How data and digital technology transformed news graphics. Barcelona: Universitat Oberta de Catalunya.

http://openaccess.uoc.edu/webapps/o2/handle/10609/66768

Caminero-Fernández, Lidia; Sánchez-García, Pilar (2018). "El perfil y formación del ciberperiodista en redacciones nativas digitales". Hipertext.net, n. 16, pp. 4-15.

https://doi.org/10.31009/hipertext.net.2018.i16.04 
Cascón-Katchadourian, Jesús-Daniel (2020). “Tecnologias para luchar contra la pandemia Covid-19: geolocalizacion, rastreo, big data, SIG, inteligencia artificial y privacidad". El profesional de la informacion, v. 29, n. 4, e290429.

https://doi.org/10.3145/epi.2020.jul.29

Caswell, David (2019). "Editorial innovation in news". BBC News Lab. Medium.com, 14 February.

https://medium.com/bbc-news-labs/editorial-innovation-in-news-fcf3aaf3d288

Chen, Baoquan; Shi, Mingyi; Ni, Xingyu; Ruan, Liangwang; Jiang, Hongda; Yao, Heyuan; Wang, Mengdi; Song, Zhenhua; Zhou, Qiang; Ge, Tong (2020). "Visual data analysis and simulation prediction for Covid-19". International journal of educational excellence, v. 6, n. 1, pp. 95-114.

https://doi.org/10.18562/IJEE.055

Chen, Zhirui; Guo, Wenchen (2020). "Innovative research on the improvement of visual quality of data journalism in China: Visual language and interaction design”. Journal of physics: Conference series, 1518012030.

https://doi.org/10.1088/1742-6596/1518/1/012030

Codina, Lluís; Iglesias-García, Mar; Pedraza-Jiménez, Rafael; García-Carretero, Lucía (2016). Search engine optimization and online journalism: The SEO-WCP framework. Barcelona: UPF. Departamento de Comunicación. Serie Editorial DigiDoc.

https://repositori.upf.edu/bitstream/handle/10230/26098/codina_search_2016.pdf

Córdoba-Cabús, Alba (2020). "Estándares de calidad en el periodismo de datos: fuentes, narrativas y visualizaciones en los Data Journalism Awards 2019". Profesional de la información, v. 29, n. 3, e290328.

https://doi.org/10.3145/epi.2020.may.28

Cover, Rob (2006). "Audience inter/active: Interactive media, narrative control and reconceiving audience history". New media \& society, v. 8, n. 1, pp. 139-158.

https://doi.org/10.1177/1461444806059922

Danielson, Megan (2020). "Notable maps visualizing Covid-19 and surrounding impact". Medium, 12 March. https://blog.mapbox.com/notable-maps-visualizing-covid-19-and-surrounding-impacts-951724cc4bd8

De-la-Peña, Nonny; Weil, Peggy; Llobera, Joan; Giannopoulos, Elias; Pomés, Ausiàs; Spanlang, Bernhard; Friedman, Doron; Sánchez-Vives, María V.; Slater, Mel (2010). “Immersive journalism: immersive virtual reality for the first-person experience of news". Presence, v. 19, n. 4, pp. 291-301.

https://doi.org/10.1162/PRES_a_00005

De-Maeyer, Juliette; Libert, Manon; Domingo, David; Heinderyckx, François; Le-Cam, Florence (2015). "Waiting for data journalism". Digital journalism, v. 3, n. 3, pp. 432-446.

https://doi.org/10.1080/21670811.2014.976415

Domingo, David (2008). "Interactivity in the daily routines of online newsrooms: Dealing with an uncomfortable myth". Journal of computer-mediated communication, v. 13, n. 3, pp. 680-704.

https://doi.org/10.1111/j.1083-6101.2008.00415.x

Dowling, David (2019). Immersive longform storytelling: Media, technology, audience. New York: Routledge. ISBN: 978 1138595422

Engebretsen, Martin; Kennedy, Helen; Weber, Wibke (2018). "Data visualization in Scandinavian newsrooms. Emerging trends in journalistic visualization practices". Nordicom review, v. 39, n. 2, pp. 3-18.

https://doi.org/10.2478/nor-2018-0007

Ferreras-Rodríguez, Eva-María (2013). “Aproximación teórica al perfil profesional del ‘Periodista de datos'”. Icono 14, v. 11 , n. 2, pp. 115-140.

https://doi.org/10.7195/ri14.v11i2.573

Ferrer-Sapena, Antonia; Calabuig, José-Manuel; Peset, Fernanda; Sánchez-del-Toro, Isabel (2020). "Trabajar con datos abiertos en tiempos de pandemia: uso de covidDATA-19”. Profesional de la información, v. 29, n. 4, e290421.

https://doi.org/10.3145/epi.2020.jul.21

Few, Stephen (2012). Show me the numbers. Oakland: Analytics Press. ISBN: 0970601972

Fink, Katherine; Anderson, Christopher W. (2015). "Data journalism in the United States". Journalism studies, v. 16, n. 4, pp. 467-481.

https://doi.org/10.1080/1461670X.2014.939852

Freixa, Pere (2018). "Content access, storytelling, and interactive media”. In: Pérez-Montoro, Mario (ed.). Interaction in digital news media, pp. 9-31. Cham: Palgrave Macmillan.

https://doi.org/10.1007/978-3-319-96253-5_2 
Freixa, Pere; Pérez-Montoro, Mario; Codina, Lluís (2020). “Active audiences and structured journalism: Questions, doubts and good practices". In: Peña-Fernández, S.; Meso-Ayerdi, K.; Larrondo-Ureta, A. (eds.). Active audiences: Empowering citizens? Discourse in the hybrid media system. McGrawHill. ISBN: 9788448620035

Freixa, Pere; Sora, Carles; Soler-Adillon, Joan; Ribas, J. Ignasi (2014). "Snow fall y A short history of the highrise: dos modelos de comunicación audiovisual interactiva del New York Times". Textual \& visual media, n. 7, pp. 185-206. https://textualvisualmedia.com/index.php/txtvmedia/article/view/89

García-Avilés, José-Alberto (2021). "Review article: Journalism innovation research, a diverse and flourishing field (2000-2020)". Profesional de la información, v. 30, n. 1, e300110.

https://doi.org/10.3145/epi.2021.ene.10

Greussing, Esther; Kessler, Sabrina-Heike; Boomgaarden, Hajo G. (2020). “Learning from science news via interactive and animated data visualizations: An investigation combining eye tracking, online survey, and cued retrospective reporting". Science communication, v. 42, n. 6, pp. 803-828.

https://doi.org/10.1177/1075547020962100

Guallar, Javier; Codina, Lluís (2018). "Journalistic content curation and news librarianship: Differential characteristics and necessary convergence". El profesional de la información, v. 27, n. 4, pp. 778-791.

https://doi.org/10.3145/epi.2018.jul.07

Hiippala, Tuomo (2017). "The multimodality of digital longform journalism". Digital journalism, v. 5, n. 4, pp. $420-442$. https://doi.org/10.1080/21670811.2016.1169197

Howe, Jeff; Bajak, Aleszu; Kraft, Dina; Wihbey, John (2017). “Collaborative, open, mobile: A thematic exploration of best practices at the forefront of digital journalism". SSRN 3036984.

https://doi.org/10.2139/ssrn.3036984

Jacob, Rachel (2020). “Visualising global pandemic: a content analysis of infographics on Covid-19”. Journal of content, community \& communication, v. 11, pp. 116-123.

https://doi.org/10.31620/JCCC.06.20/09

Jacobson, Susan; Marino, Jacqueline; Gutsche, Robert E. (2015). "The digital animation of literary journalism”. Journalism, v. 17, n. 4, pp. 527-546.

https://doi.org/10.1177/1464884914568079

Jensen, Jens F. (1998). "Interactivity: Tracking a new concept in media and communications studies". Nordicom review, n. 19 , pp. 85-202.

https://www.nordicom.gu.se/en/tidskrifter/nordicom-review-11998/interactivity-tracking-new-concept-media-andcommunication-studies

Kalatzi, Olga; Bratsas, Charalampos; Veglis, Andreas (2018). "The principles features and techniques of data journalism". Studies in media and communication, v. 6, n. 2, pp. 36-44.

https://doi.org/10.11114/smc.v6i2.3208

Karlsen, Joakim; Stavelin, Eirik (2014). “Computational journalism in Norwegian newsrooms”. Journalism practice, v. 8, n. 1, pp. 34-48.

https://doi.org/10.1080/17512786.2013.813190

Kasica, Stephen; Berret, Charles; Munzner, Tamara (2020). "Table scraps: an actionable framework for multi-table data wrangling from an artifact study of computational journalism". IEEE Transactions on visualization and computer graphics, v. 27, n. 2, pp. 957-966.

https://doi.org/10.1109/TVCG.2020.3030462

Kim, Won; Choi, Byoung-Ju; Hong, Eui-Kyeong; Kim, Soo-Kyung; Lee, Doheon. (2003). "A taxonomy of dirty data”. Data mining and knowledge discovery, v. 7, n. 1, pp. 81-99.

https://doi.org/10.1023/A:1021564703268

Kirk, Andy (2016). Data visualization. A handbook for data driven design. London: SAGE. ISBN: 9781526468925

Klanten, Robert; Ehmann, Sven; Schulze, Floyd (2011). Visual storytelling: Inspiring a new visual language. Berlin: Gestalten. ISBN: 9783899553758

Knight, Megan (2015). "Data journalism in the UK: A preliminary analysis of form and content". Journal of media practice, v. 16, n. 1, pp. 55-72.

https://doi.org/10.1080/14682753.2015.1015801

Landow, George P. (1991). HyperText: the convergence of contemporary critical theory and technology. Baltimore: Johns Hopkins University Press. ISBN: 9780801842801 
Lee, Bongshin; Riche, Nathalie-Henry; Isenberg, Petra; Carpendale, Sheelagh (2015). “More than telling a story: Transforming data into visually shared stories". IEEE Computer graphics and applications, v. 35, n. 5, pp. 84-90.

https://doi.org/10.1109/MCG.2015.99

Lee, Eun-Ju; Kim Ye-Weon (2016). "Effects of infographics on news elaboration, acquisition, and evaluation: Prior knowledge and issue involvement as moderators". New media \& society, v. 18, n. 8, pp. 1579-1598.

https://doi.org/10.1177/1461444814567982

Leonhardt, David; Rudoren, Jodi; Galinsky, Jon; Skog, Karron; Lacey, Marc; Giratikanon, Tom; Evans, Tyson (2017). Journalism that stands apart. The report of the 2020 Group.

https://www.nytimes.com/projects/2020-report/index.html

Lewis, Norman P.; Al-Nashmi, Eisa (2019). “Data journalism in the Arab region: Role conflict exposed”. Digital journalism, v. 7, n. 9, pp. 1200-1214.

https://doi.org/10.1080/21670811.2019.1617041

Link, Elena; Henke, Jakob; Möhring, Wiebke (2021). "Credibility and enjoyment through data? Effects of statistical information and data visualizations on message credibility and reading experience". Journalism studies, v. 22, n. 5, pp. 575-594.

https://doi.org/10.1080/1461670X.2021.1889398

Loosen, Wiebke; Reimer, Julius; De-Silva-Schmidt, Fenja (2020). “Data-driven reporting: An on-going (r)evolution? An analysis of projects nominated for the Data Journalism Awards 2013-2016". Journalism. v. 21, n. 9, pp. 1246-1263.

https://doi.org/10.1177/1464884917735691

López-García, Xosé; Rodríguez-Vázquez, Ana-Isabel; Pereira-Fariña, Xosé (2017). “Competencias tecnológicas y nuevos perfiles profesionales: desafíos del periodismo actual”. Comunicar, v. 25, n. 53, pp. 81-90.

https://doi.org/10.3916/C53-2017-08

Lopezosa, Carlos; Codina, Lluís; Díaz-Noci, Javier; Ontalba, José-Antonio (2020). "SEO and the digital news media: From the workplace to the classroom". Comunicar, v. 63, pp. 65-75.

https://doi.org/10.3916/C63-2020-06

McCandless, David (2014). Knowledge is beautiful: Impossible ideas, invisible patterns, hidden connections. New York: Harper Collins. ISBN: 9780062188229

McKenna, Sean; Henry Riche, Nathalie; Lee, Bongshin; Boy, Jeremy; Meyer, Miriah (2017). "Visual narrative flow: Exploring factors shaping data visualization story reading experiences". Eurographics conference on visualization (EuroVis), v. 36, n. 3, pp. 377-387.

https://docplayer.net/103936570-Visual-narrative-flow-exploring-factors-shaping-data-visualization-story-readingexperiences.html

Mcmillan, Sally J. (2002). "A four-part model of cyber-interactivity: Some cyber-places are more interactive than others". New media \& society, v. 4, n. 2, pp. 271-291.

https://journals.sagepub.com/doi/10.1177/146144480200400208

McNutt, Andrew; Kindlmann, Gordon; Correll, Michael (2020). "Surfacing visualization mirages". In: Proceedings of the $2020 \mathrm{CHI}$ Conference on human factors in computing systems, 16 pp. ISBN: 9781450367080

https://doi.org/10.1145/3313831.3376420

Nash, Kate (2014). "Clicking on the world: documentary representation and interactivity”. In: K. Nash; C. Hight; C. Summerhayes (eds.) New documentary ecologies, pp. 50-66. Palgrave Macmillan. ISBN: 9781137310491

Nelson, Theodor H. (1983). Literary machines: The report on, and of, Project Xanadu, concerning word processing, electronic publishing, hypertext, thinkertoys, tomorrow's intellectual revolution, and certain other topics including knowledge, education and freedom. Self-edited. 1992 edition by Mindful Press. ISBN: 9780893470623

Newman, Nic (2021). Journalism, media, and technology trends and predictions 2021. Oxford: Reuters Institute, University of Oxford.

https://reutersinstitute.politics.ox.ac.uk/journalism-media-and-technology-trends-and-predictions-2021

Oh, Jeeyun; Hwang, Angel-Hsung-Chi; Lim, Hayoung-Sally (2020). “How interactive data visualization and users' BMI (body mass index) influence obesity prevention intentions: The mediating effect of cognitive absorption". Health communication.

https://doi.org/10.1080/10410236.2020.1791376

Ojo, Adegboyega; Heravi, Bahareh (2018). "Patterns in award winning data storytelling". Digital journalism, v. 6, n. 6, pp. 693-718.

https://doi.org/10.1080/21670811.2017.1403291 
Palau-Sampio, Dolors; Sánchez-García, Pilar (2020). “Digital resources in the current journalistic narrative: Uses and limitations of hypertext, multimedia and interactivity". Communication \& society, v. 33, n. 2, pp. 1-16.

https://doi.org/10.15581/003.33.2.1-16

Parasie, Sylvain (2015). "Data-driven revelation? Epistemological tensions in investigative journalism in the age of 'big data'”. Digital journalism, v. 3, n. 3, pp. 364-380.

https://doi.org/10.1080/21670811.2014.976408

Parasie, Sylvain; Dagiral, Eric (2013). “Data-driven journalism and the public good: 'Computer-assisted-reporters' and 'Programmer-journalists' in Chicago". New media \& society, v. 15, n. 6, pp. 853-871.

https://doi.org/10.1177/1461444812463345

Paucar-Carrión, Katty; Coronel-Salas, Gabriela (2019). "Laboratorios: un recurso para la innovación periodística”. Revista ibérica de sistemas e tecnologias de informação, n. E20, pp. 477-489.

http://www.risti.xyz/issues/ristie20.pdf

Pavlik, John V. (2001). Journalism and new media. New York: Columbia University Press. ISBN: 9780231114837

Pentzold, Christian; Fechner, Denise (2020). “Data journalism's many futures: Diagrammatic displays and prospective probabilities in data-driven news predictions". Convergence: The international journal of research into new media technologies, v. 26, n. 4, pp. 732- 750.

https://doi.org/10.1177/1354856519880790

Pérez-Montoro, Mario (ed.) (2018) . Interaction in digital news media: From principles to practice. London, Cham: Palgrave Macmillan (Springer Nature). ISBN: 9783319962528

Pérez-Montoro, Mario (2021). "Comunicación visual de una emergencia sanitaria mundial: el caso de la Covid-19". Anuario ThinkEPI, v. 15, e15d01.

https://doi.org/10.3145/thinkepi.2021.e15d01

Pérez-Montoro, Mario; Codina, Lluís (2017). Navigation design and SEO for content-intensive websites: A guide for an efficient digital communication. Oxford: Chandos Publishing (Elsevier). ISBN: 9780081006764

Pérez-Montoro, Mario; Freixa, Pere (2018). "Interaction in digital news media: Trends, challenges, and lessons learned". In: Pérez-Montoro, Mario (ed.). Interaction in digital news media (pp. 193-201). London, Cham: Palgrave Macmillan (Springer Nature). ISBN: 9783319962528

Plaisant, Catherine (2004). "The challenge of information visualization evaluation". AVI '04 Proceedings of the working conference on Advanced visual interfaces, pp. 109-116. New York: ACM.

https://doi.org/10.1145/989863.989880

Planer, Rosanna; Godulla, Alexander (2021). "Longform journalism in the USA and Germany: Patterns in award-winning digital storytelling productions”. Journalism practice, v. 15, n. 4, pp. 566-582.

https://doi.org/10.1080/17512786.2020.1742771

Porlezza, Colin; Splendore, Sergio (2019). "From open journalism to closed data: Data journalism in Italy". Digital journalism, v. 7, n. 9, pp. 1230-1252.

https://doi.org/10.1080/21670811.2019.1657778

Pouchard, Line; Barton, Amy; Zilinski, Lisa (2014). "Data narratives: Increasing scholarly value". Proceedings of the ASIST Annual meeting, v. 51, n. 1, pp. 1-4.

https://doi.org/10.1002/meet.2014.14505101088

Roberts, Graham (2018). "Augmented reality: how we'll bring the news into your home". The New York Times, 1 February. https://www.nytimes.com/interactive/2018/02/01/sports/olympics/nyt-ar-augmented-reality-ul.html

Ryan, Marie-Laure (ed.) (2004). Narrative across media: The languages of storytelling. Lincoln: University of Nebraska Press. ISBN: 9780803245631

Salaverría, Ramón (2015). "Los labs como fórmula de innovación en los medios". El profesional de la información, v. 24, n. 4, pp. 397-404.

https://doi.org/10.3145/epi.2015.jul.06

Schultz, Tanjev (1999). "Interactive options in online journalism: a content analysis of 100 US newspapers". Journal of computer mediated communication, v. 5, n. 1, JCMC513.

https://doi.org/10.1111/j.1083-6101.1999.tb00331.x

Segel, Edward; Heer, Jeffrey (2010). "Narrative visualization: Telling stories with data”. IEEE transactions on visualization and computer graphics, v. 16, n. 6, pp. 1139-1148.

https://doi.org/10.1109/TVCG.2010.179 
Smiciklas, Mark (2012). The power of infographics: Using pictures to communicate and connect with your audiences. Indianapolis: Pearson Education. ISBN: 9780789749499

Soler-Adillon, Joan; Sora, Carles; Freixa, Pere; Ribas, J. Ignasi (2016). “Perfil del profesional de la comunicación interactiva: fundamentos, actualidad y perspectivas". El profesional de la información, v. 25, n. 2, pp. 196-208.

https://doi.org/10.3145/epi.2016.mar.06

Stikeleather, Jim (2013). "The three elements of successful data visualizations". Harvard business review. https://hbr.org/2013/04/the-three-elements-of-successf

Tang, Nan; Wu, Eugene; Li, Guoliang (2019). "Towards democratizing relational data visualization". In: Proceedings of the 2019 International conference on management of data. ACM, pp. 2025-2030.

https://doi.org/10.1145/3299869.3314029

Tejedor-Calvo, Santiago; Romero-Rodríguez, Luis M.; Moncada-Moncada, Andrés-José; Alencar-Dornelles, Mariana (2020). "Journalism that tells the future: possibilities and journalistic scenarios for augmented reality". Profesional de la información, v. 29, n. 6, e290602.

https://doi.org/10.3145/epi.2020.nov.02

Tufte, Edward R. (1983). The visual display of quantitative information. Cheshire: Graphic Press. ISBN: 1930824130

Tulloch, Christopher; Ramon, Xavier (2017). "Take five: How Sports illustrated and L'équipe redefine the long-form sports journalism genre". Digital journalism, v. 5, n. 5, pp. 652-672.

https://doi.org/10.1080/21670811.2016.1263159

Uricchio, William (2016): Mapping the intersection of two cultures: Interactive documentary and digital journalism. Cambridge: MIT Open Documentary Lab.

http://opendoclab.mit.edu/interactivejournalism

Van-Krieken, Kobie; Sanders, José (2019). "What is narrative journalism? A systematic review and an empirical agenda". Journalism, v. 22, n. 6, pp. 1393-1412.

https://doi.org/10.1177/1464884919862056

Walsh, Richard (2011). "Emergent narrative in interactive media”. Narrative, v. 19, n. 1, pp. 72-85. https://www.jstor.org/stable/41289287

Wang, Guan; Gu, Wenying; Suh, Ayoung (2018). "The effects of 360-degree VR videos on audience engagement: evidence from The New York Times". International conference on $\mathrm{HCl}$ in business, government, and organizations, pp. $217-235$. Cham: Springer.

https://doi.org/10.1007/978-3-319-91716-0_17

Wang, Yixue; Diakopoulos, Nicholas (2021). "Journalistic source discovery: Supporting the identification of news sources in user generated content". Proceedings of the $2021 \mathrm{CHI}$ Conference on human factors in computing systems, CHI (v. 21) [pre-print].

http://www.nickdiakopoulos.com/wp-content/uploads/2021/04/UGC_sourcing_CHI_author_generated.pdf

Weber, Wibke; Rall, Hannes (2012). "Data visualization in online journalism and its implications for the production process". IEEE $16^{\text {th }}$ International conference on information visualisation, pp. 349-356.

https://doi.org/10.1109/IV.2012.65

Winograd, Terry (1997). "From computing machinery to interaction design”. In: Denning, Peter J.; Metcalfe, Robert M. Beyond calculation the next fifty years of computing. New York: Springer-Verlag, pp. 149-162. ISBN: 0387985883 http://hci.stanford.edu/ winograd/papers/acm97.html

Young, Mary-Lynn; Hermida, Alfred; Fulda, Johanna (2017). "What makes for great data journalism? A content analysis of data journalism awards finalists 2012-2015". Journalism practice, v. 12, n. 1, pp. 115-135. https://doi.org/10.1080/17512786.2016.1270171

Zamith, Rodrigo (2019). "Transparency, interactivity, diversity, and information provenance in everyday data journalism". Digital journalism, v. 7, n. 4, pp. 470-489.

https://doi.org/10.1080/21670811.2018.1554409 